D.O.I: $10.3895 / \mathrm{S} 1808-04482013000100006$

\title{
ROBOCANO: UMA DINÂMICA ALTERNATIVA PARA ENSINAR E APRENDER GESTÃ̃ DA PRODUÇÃO
}

\section{ROBOCANO: AN ALTERNATIVE ACTIVITY TO TEACH AND LEARN PRODUCTION MANAGEMENT}

\author{
Luciano Costa Santos $^{1}$; Cláudia Fabiana Gohr ${ }^{2}$; Milton Vieira Junior ${ }^{3}$ \\ ${ }^{1}$ Universidade Federal da Paraíba - UFPB - João Pessoa/PB - Brasil \\ luciano@ct.ufpb.br \\ ${ }^{2}$ Universidade Federal da Paraíba - UFPB - João Pessoa/PB - Brasil \\ claudiagohr@ct.ufpb.br \\ ${ }^{3}$ Universidade Nove de Julho - UNINOVE - São Paulo/SP - Brasil \\ mvieirajr@uninove.br
}

\begin{abstract}
Resumo
O objetivo deste artigo é apresentar uma dinâmica para o ensino de Gestão da Produção que propõe a aplicação de conexões de PVC, normalmente utilizadas em instalações hidráulicas, para simular operações de montagem que são comuns na indústria. O método de ensino seguiu a lógica dos modelos de educação cooperativa e colaborativa e foi desenvolvido em uma abordagem de pesquisa-ação, uma vez que as atividades propostas foram testadas e aperfeiçoadas durante as aplicações feitas em laboratórios de ensino. A aplicabilidade do método foi confirmada pelo feedback positivo recebido dos alunos envolvidos, obtido através de uma pesquisa realizada após um conjunto de aplicações. A atividade com conexões hidráulicas representa um exercício prático que contribui para a redução da lacuna entre teoria e prática no ensino de Gestão de Produção. Utilizando materiais simples e de baixo custo, os alunos são induzidos a simular um processo real a partir de um produto fictício.
\end{abstract}

Palavras-chave: dinâmicas de ensino; aprendizagem vivencial; gestão da produção.

\section{Introdução}

O processo de ensino-aprendizagem tem passado por alterações significativas nos últimos anos. Partiu-se de um processo de educação passiva, na qual o estudante simplesmente recebia os ensinamentos do mestre sem questionamentos ou mesmo participação, chegando-se a modelos de ensino que privilegiam a participação e a integração do aluno, além da interação com o professor e com os colegas. Seguindo essa tendência, métodos experimentais de ensino-aprendizagem recebem, cada vez mais, atenção nas pesquisas e despertam interesse em educadores e estudantes (HAAPASALO; HYVÖNEN, 2001). 
Reconhecendo a necessidade das instituições de ensino em preparar melhor seus estudantes para o "mundo real", Mello (1998) identificou a existência de um fortalecimento das atividades de práticas extraclasses (hands-on) e da valorização das chamadas atividades work-for-credit, nas quais os alunos são levados efetivamente a desempenhar funções profissionais numa proporção mais intensa do que se espera nos tradicionais estágios curriculares. No que se refere a metodologias, Magill e Roy (2007) sugerem que os métodos atuais de ensino devem encorajar os estudantes a participarem de forma criativa no desenvolvimento de atividades lúdicas.

As mudanças nas metodologias e ferramentas utilizadas pelos docentes foram motivo de preocupação abordado por Moscinski (2007), que destacou a importância de utilizar-se de práticas de laboratório, de desenvolvimento de projetos e de recursos computacionais, e afirmou que os estudantes devem não apenas saber utilizar recursos e ferramentas, mas compreender seu funcionamento e sua fundamentação conceitual. Esse é, na opinião de Moscinski (2007), o principal desafio do papel que o docente deve desempenhar no processo de formação do profissional.

No âmbito da Engenharia de Produção, as atividades realizadas em laboratórios de ensino de conteúdos específicos têm recebido uma ênfase cada vez maior, representando um tema recorrente nas discussões do Grupo de Trabalho (GT) de Graduação durante os Encontros de Coordenadores (ENCEP) e os Encontros Nacionais (ENEGEP) da Associação Brasileira de Engenharia de Produção (ABEPRO, 2012). Dentre outros benefícios didáticos, os laboratórios de ensino de conteúdos específicos permitem simular processos, reproduzindo virtualmente algumas das situações reais do ambiente industrial.

Procurando contribuir para a estruturação de aulas práticas e atividades lúdicas, este artigo tem o objetivo de apresentar uma dinâmica de ensino que tem demonstrado uma boa aceitação e tem despertado o interesse de estudantes de cursos de graduação em Engenharia de Produção. Essa dinâmica propõe a aplicação de conexões roscáveis de PVC (cloreto de polivinila), normalmente utilizadas em instalações hidráulicas, para simular operações de montagem que são comuns em grande parte dos setores industriais.

A atividade didática apresentada neste artigo foi idealizada por meio de um projeto de ensino que tinha o objetivo de criar dinâmicas de aprendizagem em disciplinas da área de Gestão da Produção, que corresponde à área de "Engenharia de Operações e Processos da Produção", estabelecida pela Associação Brasileira de Engenharia de Produção (ABEPRO, 2012). As conexões de PVC foram escolhidas por atender a três requisitos básicos: baixo custo, intercambialidade e facilidade de montagem (dispensando o uso de ferramentas). Quando unidas umas às outras, as conexões permitem formar diferentes combinações que representam produtos fictícios a serem produzidos em uma fábrica simulada. Devido ao fato de as primeiras montagens desses produtos fictícios se assemelharem a uma espécie de robô de brinquedo, o projeto de ensino foi denominado 
de ROBOCANO.

Além de as conexões de PVC possibilitarem a criação de uma infinidade de produtos e processos de montagem, a sua utilização didática auxilia na compreensão de diversas técnicas de Gestão da Produção, tais como, estudo de tempos e métodos, balanceamento de linhas de montagem, sistema MRP (Material Requirements Planning), programação puxada e kanban, dentre outras. Na verdade, a sua utilização didática pode facilitar a compreensão de quaisquer técnicas que adotem o clássico princípio da intercambialidade de peças, um dos pilares do desenvolvimento da concepção moderna de Gestão da Produção (FORD, 2005; SCHMENNER, 2001).

Embora a dinâmica proposta tenha um amplo leque de possibilidades de uso, o projeto de ensino relatado neste artigo abordou três tópicos específicos:

- Aplicação 1: estudo de tempos e balanceamento de linhas de montagem.

- Aplicação 2: planejamento de necessidades de materiais (MRP).

- Aplicação 3: programação puxada com o sistema kanban.

O artigo inicialmente apresenta uma breve revisão de literatura que identifica algumas metodologias de ensino mais recentemente utilizadas e destaca a aplicação de jogos didáticos e atividades lúdicas em Gestão da Produção. Em seguida, o artigo descreve detalhadamente a metodologia de desenvolvimento do Projeto ROBOCANO. O texto prossegue com o relato de três aplicações práticas da dinâmica, relacionadas com os tópicos abordados no projeto. Nas duas últimas seções são discutidos os resultados preliminares do projeto e apresentadas as considerações finais do trabalho.

\section{Novas abordagens de ensino-aprendizagem}

Diante da obsolescência do modelo tradicional de educação, surgem novas abordagens e metodologias que estimulam a participação do estudante no processo de ensino-aprendizagem. Dentre essas novas abordagens, esta seção destaca as seguintes tendências para o ensino de engenharia: educação cooperativa, educação colaborativa, aprendizagem baseada em problemas, e o uso de jogos e atividades lúdicas.

Considerado um dos mais destacados e férteis métodos de ensino, pesquisa e prática disseminados pelas teorias de educação, a educação cooperativa só acontece quando os estudantes atuam conjuntamente para a consecução de um objetivo, e estes só são alcançados quando todos os membros do grupo obtêm sucesso na aprendizagem (JOHNSON; JOHNSON; STANNE, 2000).

Prática educacional largamente utilizada nas últimas décadas, em todos os níveis de formação (JOHNSON; JOHNSON; STANNE, 2000), a educação cooperativa apresenta uma abordagem de criação, análise e aplicação sistemática de interações sociais livres no ambiente de 
aula, em contraposição à abordagem competitiva que era anteriormente utilizada. As pesquisas que descrevem e aplicam a educação cooperativa indicam ser esta abordagem uma das que obtiveram maior sucesso no campo educacional, o que é demonstrado, em geral, pelos resultados alcançados pelos estudantes em cuja formação o método foi aplicado (SLAVIN, 1995).

A educação cooperativa, segundo Panitz (1996), pode ser definida como um conjunto de processos de interações em grupo visando atingir um objetivo comum. Dentro dessa ótica, Slavin (1995) apresentou as quatro principais perspectivas teóricas sob as quais a educação cooperativa deve ser embasada: motivação, coesão social, cognição e desenvolvimento, e formalizou um modelo de relação entre essas perspectivas, conforme mostra a Figura 1.

Figura 1 - Modelo de desenvolvimento para a educação cooperativa.

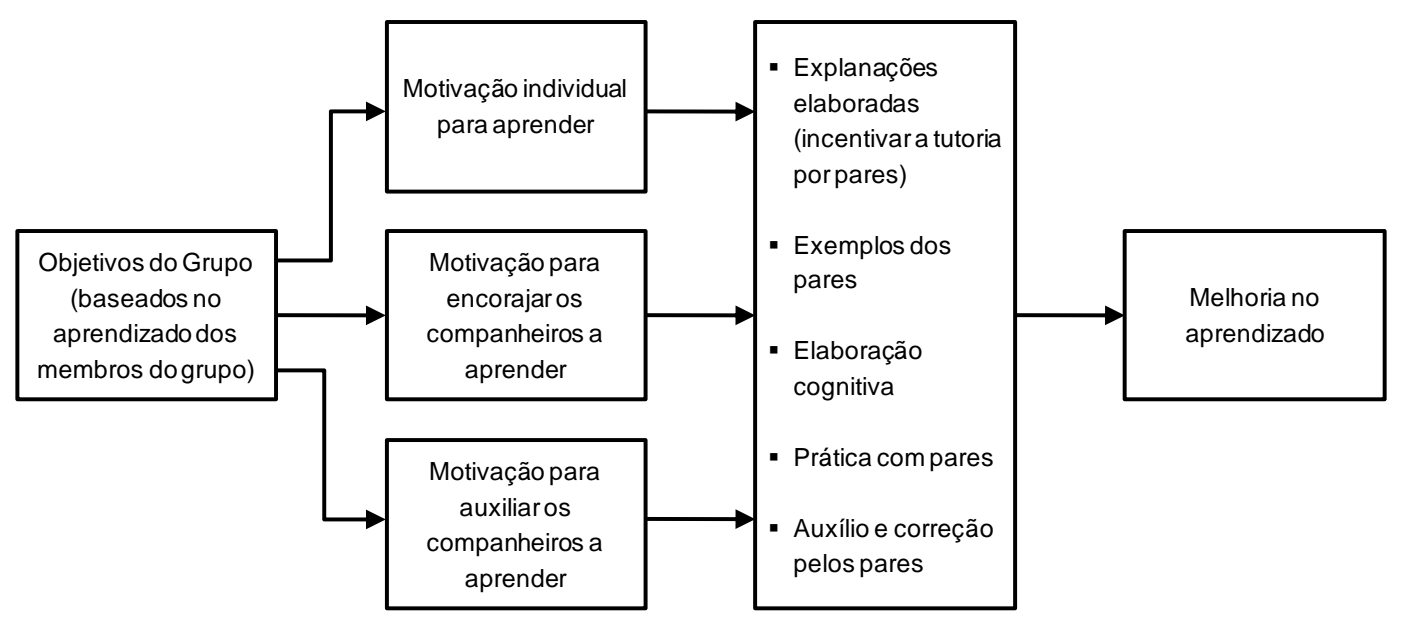

Fonte: Adaptado de Slavin (1995).

Outra abordagem relevante para o ensino de engenharia é a educação colaborativa. De acordo com Panitz (1996), a educação colaborativa é uma filosofia de interação com participação individual e não uma técnica de grupo, diferenciando-se da educação cooperativa sob esse aspecto. Nesse caso, a interação entre os indivíduos representa o meio para facilitar a realização dos objetivos individuais de aprendizagem.

Dillenbourg (1999) afirma que a definição mais abrangente, porém não satisfatória, de educação colaborativa é: uma situação na qual duas ou mais pessoas aprendem (ou tentam aprender) algo em conjunto e com objetivos comuns. Em resumo, a expressão "educação colaborativa" deve descrever uma situação na qual são esperadas formas particulares de interação entre pessoas, mas sem a garantia de que efetivamente ocorram.

Gokhale (1995) observou que estudantes que participaram de experiências ativas de educação colaborativa obtêm melhor desempenho em testes de análise crítica do que alunos que estudaram de forma individualizada. Ganha então projeção a ideia de que o papel do docente na educação colaborativa passa a ser mais o de um facilitador do processo de aprendizagem, 
vislumbrando o ensino como uma ação de desenvolver nos alunos a capacidade e a habilidade de aprender (GOKHALE, 1995).

Em meio às abordagens de educação cooperativa e colaborativa, surge a Aprendizagem Baseada em Problemas (Problem-Based Learning - PBL) como uma estratégia de ensino que visa promover o aprendizado de forma ativa e participativa. Nesse modelo, o estudante deve ser levado a analisar problemas reais e identificar os conhecimentos necessários para solucioná-los, apreendendo-os (BENJAMIN; KEENAN, 2006).

O PBL parte da premissa que a identificação e a resolução de um problema representam o melhor meio de se aprender, pois um simples problema pode abranger o aprendizado de diversos aspectos que influenciam no aprendiz (YEO, 2005). Yeo (2005) define o PBL como sendo um processo interativo que é motivado pela existência de um problema real que envolve os estudantes em sua solução. Para tanto, é necessário que os alunos procurem conceitos e conhecimentos necessários para a formulação da solução.

Outra estratégia que tem ganhado popularidade nos últimos anos é a utilização de jogos e atividades lúdicas como instrumentos didáticos. Na educação infantil, jogos e brincadeiras despertam a criatividade e encorajam a experimentação e a tomada de decisões, habilidades desejadas em profissionais de todas as áreas (ROSSITER, 2007). Na educação de jovens e adultos, jogos e atividades lúdicas podem ter efeitos semelhantes, desde que sejam adaptados para este público e para o nível de conhecimento compatível com a formação. Lewis e Maylor (2007) afirmam que a utilização de atividades lúdicas provoca o aprendizado empírico por meio de experiências concretas que permitem ao estudante explorar a teoria e aplicá-la de modo mais crítico.

Jogos instrucionais vêm se disseminando rapidamente, apesar de a literatura pouco registrar a respeito dos benefícios obtidos por essa metodologia de ensino (BARDON; JOSSERAND, 2009). Isso pode ser creditado à falta de esquemas conceituais que permitam a compreensão do processo educacional envolvido no uso das atividades lúdicas, e à falta de uma ampla orientação sobre como desenvolver e aplicar os conteúdos aprendidos nos jogos (LEWIS; MAYLOR, 2007).

\section{Dinâmicas de ensino-aprendizagem em Gestão da Produção}

No que se refere ao ensino de Gestão da Produção, Lewis e Maylor (2007) lembram que os jogos e as simulações práticas já são utilizados nessa área desde a década de 1960 e citam o Beer Game, o Cuppa Manufacturing Game e o Training Factory, dentre os jogos mais populares. Embora tenha tradição na área, a disseminação desse tipo de atividade didática ainda é modesta, o que revela a necessidade latente de desenvolvimento e aplicação de atividades interativas como estratégias de ensino-aprendizagem.

Dentre as modalidades de jogos e atividades lúdicas utilizadas no ensino de Gestão da 
Produção, destacam-se as simulações. Quando aplicadas como ferramentas didáticas, as simulações têm o objetivo de representar situações reais que dificilmente poderiam ser reproduzidas em sala de aula, motivando os estudantes a tomar decisões e a trabalhar em equipe para resolver problemas similares àqueles que encontrarão em sua vida profissional.

Com o desenvolvimento da tecnologia de informação e comunicação, as simulações computacionais têm se proliferado rapidamente no ensino de Gestão da Produção. No entanto, Smeds (2003) destaca que, além de modelos computacionais, são utilizados modelos conceituais, principalmente quando o comportamento de um sistema não pode ser expresso por meio de algoritmos e dados numéricos. Segundo a autora, esses modelos são orientados para as interações humanas entre os participantes daquilo que ela denomina de "simulação social".

Com o objetivo de contribuir para a disseminação de atividades lúdicas que enfatizam a aprendizagem por meio da experiência, Ammar e Wright (1999) apresentam oito atividades realizadas em sala de aula para o ensino de Gestão da Produção, dentre as quais, são descritas simulações computacionais e atividades que utilizam recursos físicos, como por exemplo, bloquinhos de montagem de brinquedo (conhecidos comercialmente pela marca LEGO $^{\circledR}$ ). Nas atividades que utilizam peças LEGO $^{\circledR}$, Ammar e Wright (1999) propõem a sua aplicação em exercícios para a aprendizagem de conceitos de programação linear e balanceamento de linhas de montagem.

A aplicação de blocos de montagem LEGO $^{\circledR}$ também foi descrita por Paxton (2003) em uma atividade que facilita o entendimento do conceito de curva de aprendizagem. Snider e Eliasson (2009), por sua vez, utilizaram os blocos $\mathrm{LEGO}^{\circledR}$ em um exercício que demonstra as diferenças entre a produção puxada e a produção empurrada, além de ilustrar como o sistema just-in-time pode ser combinado com a filosofia de customização de massa. Seguindo a mesma linha, Depexe et al. (2006) utilizaram os bloquinhos LEGO $^{\circledR}$ para simular a montagem de carrinhos de brinquedo, com o objetivo de ensinar os princípios básicos da produção enxuta. Com outra abordagem, SmithDaniels e Smith-Daniels (2008) aplicaram esses mesmos recursos didáticos para o ensino de conceitos essenciais de gerenciamento de projetos.

De fato, a utilização dos recursos baseados em peças LEGO $^{\circledR}$ tem sido tão popular que já é possível encontrar sua aplicação em disciplinas de outras áreas. Por exemplo, Bürgi e Roos (2003) defenderam seu uso no processo de análise e formulação de estratégias empresariais, desenvolvendo uma metodologia para facilitar a visualização metafórica do processo decisório em workshops de executivos.

Além dos exemplos citados, também são descritas na literatura outras dinâmicas com processos simulados fisicamente. Por exemplo, Costa e Jungles (2005) descreveram uma atividade didática feita com canetas esferográficas para o estudo do mapeamento do fluxo de valor. Já Lage 
Junior e Fernandes (2005) utilizaram protótipos de madeira para ensino do funcionamento do sistema kanban de duplo cartão. Có, Có e Merigueti (2008), por sua vez, utilizaram cartas de baralho para desenvolver um jogo didático sobre o conceito de heyjunka, um dos pilares da filosofia de produção enxuta.

O sucesso das metodologias baseadas em peças simples e brinquedos de montagem podem ser explicados por sua facilidade de aplicação e pelo interesse que eles despertam nos alunos. No ensino de Gestão da Produção, em particular, eles proporcionam a intercambialidade de peças e a facilidade de simular processos de produção em pequena escala.

\section{Metodologia}

O desenvolvimento do Projeto ROBOCANO ocorreu em três fases, tal como mostra a Figura 2. Embora a Figura dê uma noção de sequência, o desenvolvimento da dinâmica e a realização de suas aplicações foi interativo, permitindo o feedback ao longo de todo o processo. Esse feedback é representado na Figura pelas setas tracejadas que retornam às fases anteriores.

Figura 2 - Fases do Projeto ROBOCANO.

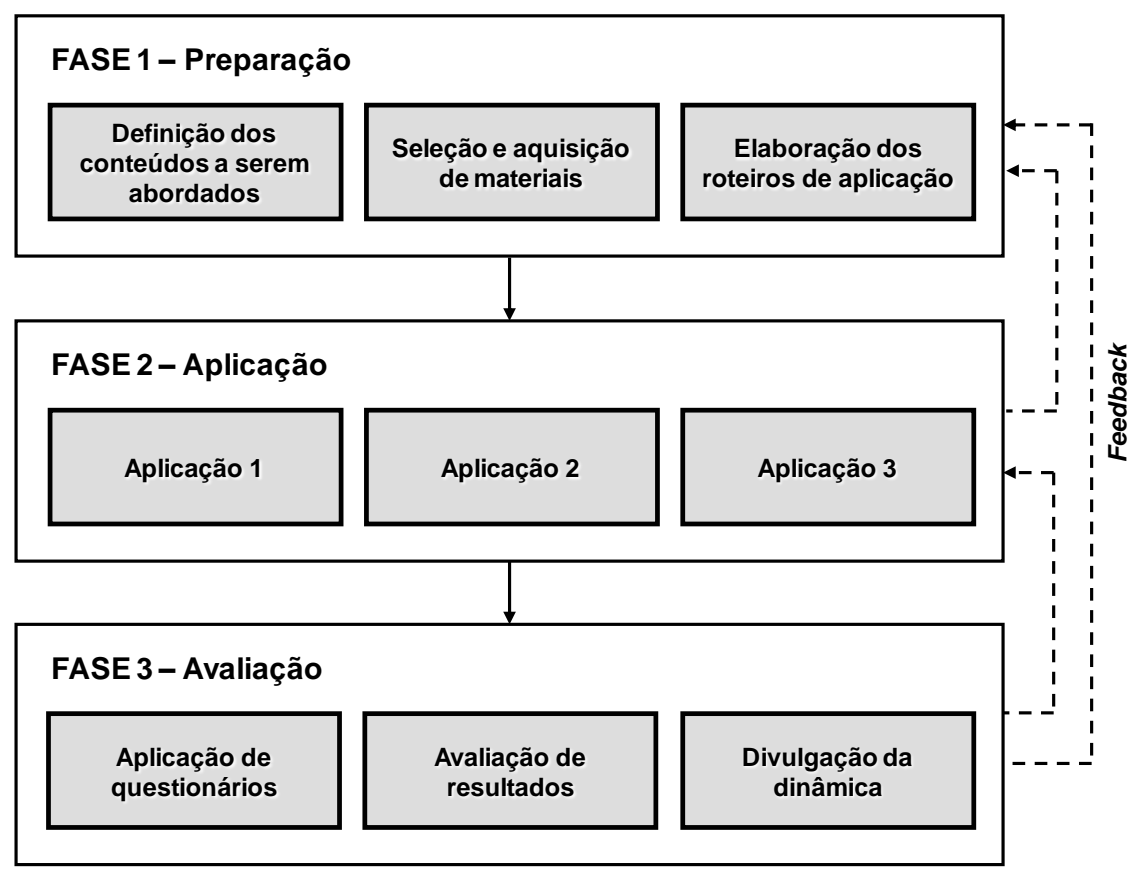

A primeira fase do projeto foi iniciada com a definição dos conteúdos que seriam abordados, pois isso influenciaria em todo o desenvolvimento posterior do projeto. Assim, foi estabelecido que a dinâmica fosse aplicada aos seguintes tópicos: estudo de tempos, balanceamento de linhas de montagem, sistema MRP e sistema kanban. A escolha dos tópicos foi motivada pela dificuldade comumente demonstrada pelos estudantes em visualizar a aplicação prática desses conceitos quando se seguia a tradicional sequência exposição-exercício feita em sala de aula. Nesse sentido, 
considerou-se oportuna a simulação de processos de montagem para facilitar a aprendizagem desses tópicos.

$\mathrm{Na}$ fase de preparação foi escolhido o conjunto de peças que seria usado, observando a versatilidade necessária para permitir a formação de diferentes produtos com conexões de PVC. Para isso, foi formulada uma lista de componentes orientada para a montagem de um tipo específico de produto com diferentes variações (ver a Tabela 1 e a Figura 3).

Tabela 1 - Lista de componentes por unidade.

\begin{tabular}{lc}
\hline Item & Quantidade \\
\hline Bucha de redução roscável 3/4"x1/2" & 1 \\
Cap roscável 3/4" & 5 \\
Joelho 45 roscável 3/4" & 1 \\
Joelho 90 roscável 1/2" & 3 \\
Junção 45 roscável 1/2" & 1 \\
Nípel roscável 1/2" & 7 \\
Nípel roscável 3/4" & 6 \\
Plug roscável 1/2" & 1 \\
Plug roscável 3/4" & 1 \\
Tê de redução roscável 3/4"x1/2" & 2 \\
Tê roscável 1/2" & 1 \\
Tê roscável 3/4" & 1 \\
\hline
\end{tabular}

Figura 3 - Componentes e variações do ROBOCANO.
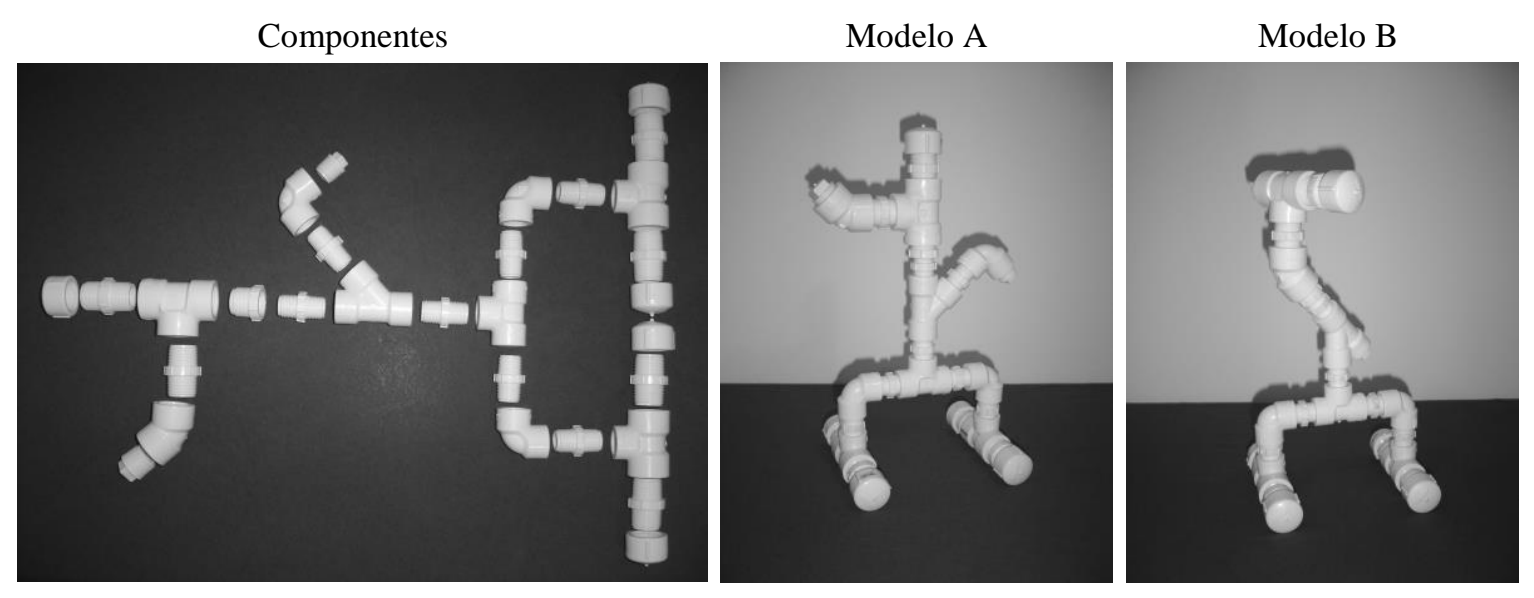

A lista de componentes da tabela 1 indica a quantidade necessária para montar apenas um kit ROBOCANO. Como o projeto previa a simulação de uma pequena fábrica em operação, foram adquiridos 40 kits. Além disso, foram providenciados contenedores para armazenar os diferentes tipos de componentes.

Na fase de preparação foram elaborados os roteiros de aplicação e os formulários de trabalho para registro e análise de dados. Os roteiros foram responsáveis por guiar a montagem das peças, 
que poderia ser feita manualmente, sem a necessidade do uso de ferramentas e equipamentos sofisticados. Também foi necessário preparar os locais para as aplicações da dinâmica, que normalmente ocorriam em laboratórios didáticos, nos quais eram formadas bancadas para a montagem das peças.

Após a fase de preparação, o projeto prosseguiu com a fase de aplicação. Conforme foi mencionado na introdução deste artigo, foram desenvolvidos três tipos de aplicação:

- Aplicação 1: estudo de tempos e balanceamento de linhas de montagem.

- Aplicação 2: planejamento de necessidades de materiais (MRP).

- Aplicação 3: programação puxada com o sistema kanban.

As aplicações foram realizadas em três disciplinas diferentes do curso de graduação em Engenharia de Produção, ao longo de três semestres letivos. Cada um dos três tipos de aplicação era realizado em uma disciplina distinta, de forma que os estudantes pudessem aprender e relacionar conceitos diferentes por meio de um mesmo recurso didático.

Para que a aplicação pudesse ser mais proveitosa em termos de aprendizagem, a dinâmica era realizada em aulas posteriores ao contato inicial dos alunos com os tópicos de estudo abordados, contato esse que ocorria por meio de aulas teóricas e pelo acesso à bibliografia básica das disciplinas. Embora a revisão teórica sobre os tópicos abordados na dinâmica esteja fora do escopo deste artigo, para o embasamento conceitual das aplicações em turmas de graduação podem-se indicar bons livros-texto na área de Planejamento e Controle da Produção (TUBINO, 2009; LUSTOSA et al, 2008; CORRÊA; GIANESI; CAON, 2007) e, com uma abordagem mais genérica, na área de Administração da Produção (KRAJEWSKY; RITZMAN; MALHOTRA, 2009; GAITHER; FRAZIER, 2001).

Do ponto de vista da metodologia científica, pode-se afirmar que o desenvolvimento da dinâmica seguiu a abordagem da pesquisa-ação (COUGHLAN; COGHLAN, 2002), uma vez que as atividades propostas foram testadas e aperfeiçoadas durante as aplicações. Na pesquisa-ação o pesquisador intervém na realidade organizacional e envolve o objeto pesquisado para o alcance dos objetivos da pesquisa (EDEN; HUXHAM, 1996). A condução do processo por um professor facilitador estimulava as interações entre os alunos, que forneciam um feedback imediato para a melhoria da dinâmica. De fato, pode-se afirmar que o desenvolvimento da dinâmica foi resultado de uma construção coletiva.

A terceira fase do projeto teve o objetivo de obter um feedback posterior à aplicação, de modo que a dinâmica e suas aplicações pudessem ser melhoradas. Para isso, foi elaborado um questionário para verificar os impactos que as atividades propostas poderiam causar nos estudantes 
que estiveram envolvidos na dinâmica. O questionário era composto por quatro perguntas básicas, relacionadas aos diferentes objetivos da dinâmica:

- Aprendizagem: A sua participação na dinâmica ROBOCANO facilitou a sua aprendizagem dos conceitos teóricos da disciplina?

- Motivação e envolvimento: A aplicação da dinâmica ROBOCANO tornou a aula mais interessante e lhe motivou a participar mais da disciplina?

- Percepção da prática: A dinâmica ROBOCANO permitiu que você pudesse entender melhor como funciona a(s) técnica(s) aplicada(s) em situações reais?

- Trabalho em equipe: Em sua opinião, a aplicação da dinâmica ROBOCANO estimula o trabalho em equipe?

Para cada pergunta, eram oferecidas cinco alternativas de resposta, seguindo o padrão usual da escala do tipo Likert: "concordo totalmente", "concordo", "não concordo nem discordo", "discordo", "discordo totalmente".

O questionário foi entregue (pessoalmente e por e-mail) para todos os estudantes que participaram da dinâmica, pertencentes a duas turmas que, juntas, somavam 70 alunos matriculados. É importante ressaltar que o questionário facultava o direito do respondente de se manter anônimo, evitando constrangimentos e minimizando o potencial de viés nos resultados.

Do total de questionários enviados, foram obtidos 31 questionários respondidos dentro do período delimitado para a avaliação. Considerando a natureza da população (finita) e das variáveis analisadas (qualitativas), o número de questionários respondidos corresponderia a uma amostra representativa do universo de 70 alunos matriculados, caso fosse adotado um nível de confiança de $90 \%$ e uma margem de erro de aproximadamente $11 \%$. No entanto, considerando o absenteísmo natural dos estudantes de graduação, estima-se que o número real de participantes tenha sido menor que o número de matriculados, o que pode conferir uma margem de erro menor e, consequentemente, um potencial maior de generalização de resultados.

Além dos resultados do questionário e da análise agregada das diferentes aplicações, considerou-se que a divulgação da dinâmica também seria parte da fase de avaliação, pois a discussão do assunto com um público mais amplo poderia fornecer novas ideias para melhorar a dinâmica. Embora seu escopo principal já tenha sido encerrado, o Projeto ROBOCANO ainda está em andamento na sua atividade de divulgação. Além da divulgação por meio deste artigo, a dinâmica já foi apresentada em trabalhos submetidos a congressos e em minicursos e oficinas didáticas ministrados em eventos de Engenharia de Produção.

Na próxima seção são demonstrados os três tipos de aplicação que foram realizados com a dinâmica que foi desenvolvida no projeto. 


\section{Aplicações do ROBOCANO}

A dinâmica foi aplicada em duas turmas diferentes do curso de graduação em Engenharia de Produção, ao longo de três semestres letivos. Cada turma participou de duas aplicações diferentes, de modo que os estudantes puderam entender a relação entre os conceitos de duas disciplinas. A seguir, relata-se uma experiência de aplicação para cada tipo.

\subsection{Aplicação 1: estudo de tempos e balanceamento de linhas de montagem}

O objetivo desta aplicação era fazer com que os estudantes tivessem a oportunidade de projetar uma linha de produção, desde a definição do método de montagem até a medição e o balanceamento dos tempos produtivos.

Ao iniciar a aplicação, o professor facilitador dividiu a turma em grupos e forneceu o roteiro da atividade, descrito resumidamente abaixo:

- Descrever (individualmente) o processo de montagem do ROBOCANO.

- Analisar (em grupo) o método de montagem de cada membro da equipe e propor um método melhorado.

- Dividir a operação em elementos de trabalho, medir os tempos e determinar o tempo padrão.

- De acordo com os dados obtidos e com a demanda requerida, projetar e balancear a linha de montagem.

Neste roteiro sugerido adotou-se o pressuposto de que o produto já tinha seu modelo definido previamente. Entretanto, uma alternativa interessante seria pedir que os alunos desenvolvessem um novo modelo de ROBOCANO a partir do conjunto de peças que era entregue para cada grupo.

Além de receber o roteiro da atividade, cada equipe formada por 4 ou 5 estudantes recebeu a fotografia e a lista de componentes de um modelo de ROBOCANO previamente definido. Neste caso, foi escolhido para montagem o "Modelo A", apresentado na Figura 3.

No início da atividade, os alunos montavam individualmente o produto e descreviam detalhadamente seu processo para que, em seguida, pudessem discutir em grupo sobre os métodos de montagem mais eficientes. O processo melhorado era documentado em um fluxograma simples.

Em seguida, os alunos mediam o tempo de cada elemento de trabalho da operação e registravam os dados em uma folha de cronometragem, repetindo a medição até completar uma amostra inicial de dez ciclos de cronometragem. Como os alunos ainda estavam em treinamento no processo de montagem, a amostra de dez cronometragens geralmente não era suficiente para atender a confiabilidade requerida e o grau de precisão desejado, devido ao grande desvio padrão das 
medidas. Porém, considerando o tempo limitado da aula, o professor esclarecia aos alunos sobre a necessidade de se realizar mais cronometragens, mas aceitava a média das primeiras cronometragens para dar prosseguimento ao trabalho.

Um fator que merece destaque é que os alunos utilizavam seus próprios telefones celulares para cronometrar as operações. Atualmente, os modelos mais comuns de telefone celular permitem armazenar na memória um número razoável de tempos, sem a necessidade de parar o cronômetro. Isso contribui para a simplicidade e o baixo custo da aplicação, já que a mesma dispensa a necessidade de utilização de cronômetros industriais.

Além da medição direta dos tempos do processo, foram estabelecidos o fator de ritmo do operador e as tolerâncias das operações para que fosse obtido o tempo padrão dos elementos. A Tabela 2 mostra um extrato da folha de cronometragem preenchida por uma das equipes de estudantes que foi formada.

Tabela 2 - Extrato de uma das folhas de cronometragem utilizadas.

\begin{tabular}{|c|l|c|c|c|c|c|}
\hline \multicolumn{2}{|c|}{ Elementos de trabalho } & $\begin{array}{c}\text { Tempo médio } \\
\text { cronometrado } \\
(\text { segundos })\end{array}$ & $\begin{array}{c}\text { Fator de } \\
\text { ritmo } \\
(\%)\end{array}$ & $\begin{array}{c}\text { Tempo } \\
\text { normal } \\
(\text { segundos })\end{array}$ & $\begin{array}{c}\text { Tolerâncias } \\
(\%)\end{array}$ & $\begin{array}{c}\text { Tempo } \\
\text { padrão } \\
(\text { segundos })\end{array}$ \\
\hline 1 & Montar pés & 16,04 & 100,00 & 16,04 & 12,00 & 17,96 \\
\hline 2 & Montar quadril & 7,94 & 100,00 & 7,94 & 12,00 & 8,89 \\
\hline 3 & Montar pernas & 14,33 & 100,00 & 14,33 & 12,00 & 16,05 \\
\hline 4 & Montar tronco & 7,19 & 100,00 & 7,19 & 12,00 & 8,05 \\
\hline 5 & Montar braço 1 & 5,53 & 100,00 & 5,53 & 12,00 & 6,19 \\
\hline 6 & Montar braço 2 & 6,32 & 100,00 & 6,32 & 12,00 & 7,08 \\
\hline 7 & Montar tronco no quadril & 7,33 & 100,00 & 7,33 & 12,00 & 8,21 \\
\hline 8 & Montar cabeça no tronco & 4,32 & 100,00 & 4,32 & 12,00 & 4,84 \\
\hline & & 69,00 & - & 69,00 & & - \\
\hline
\end{tabular}

Para agilizar a realização das cronometragens dentro do tempo da aula, é possível deixar alguns componentes pré-montados. O exemplo da Tabela 2 apresenta os tempos de montagem para esta situação. Em casos que a montagem é feita a partir de todas as peças separadas, o tempo total de montagem geralmente se aproxima do dobro daquele apresentado na Tabela 2.

Após a determinação do tempo padrão dos elementos, os estudantes deveriam estabelecer a ordem de precedência que as atividades seriam executadas. Como se tratava de um processo simples, no qual as partes do produto poderiam ser montadas quase que independentemente, o professor facilitador estabeleceu alguns critérios de precedência para enriquecer a resolução do problema de balanceamento de linha. No entanto, a definição das atividades predecessoras e a construção da rede de atividades era uma tarefa exclusiva dos alunos. A Figura 4 mostra o diagrama de precedências da mesma equipe que preencheu a Tabela 2. A partir desse diagrama de precedência, o grupo de alunos realizou o balanceamento de linha para uma demanda (estabelecida 
pelo professor) de 125 unidades por hora (ou 1000 unidades por dia, para um regime de trabalho de um único turno de 8 horas). Os resultados também são mostrados na Figura 4.

Figura 4 - Balanceamento da linha de montagem.

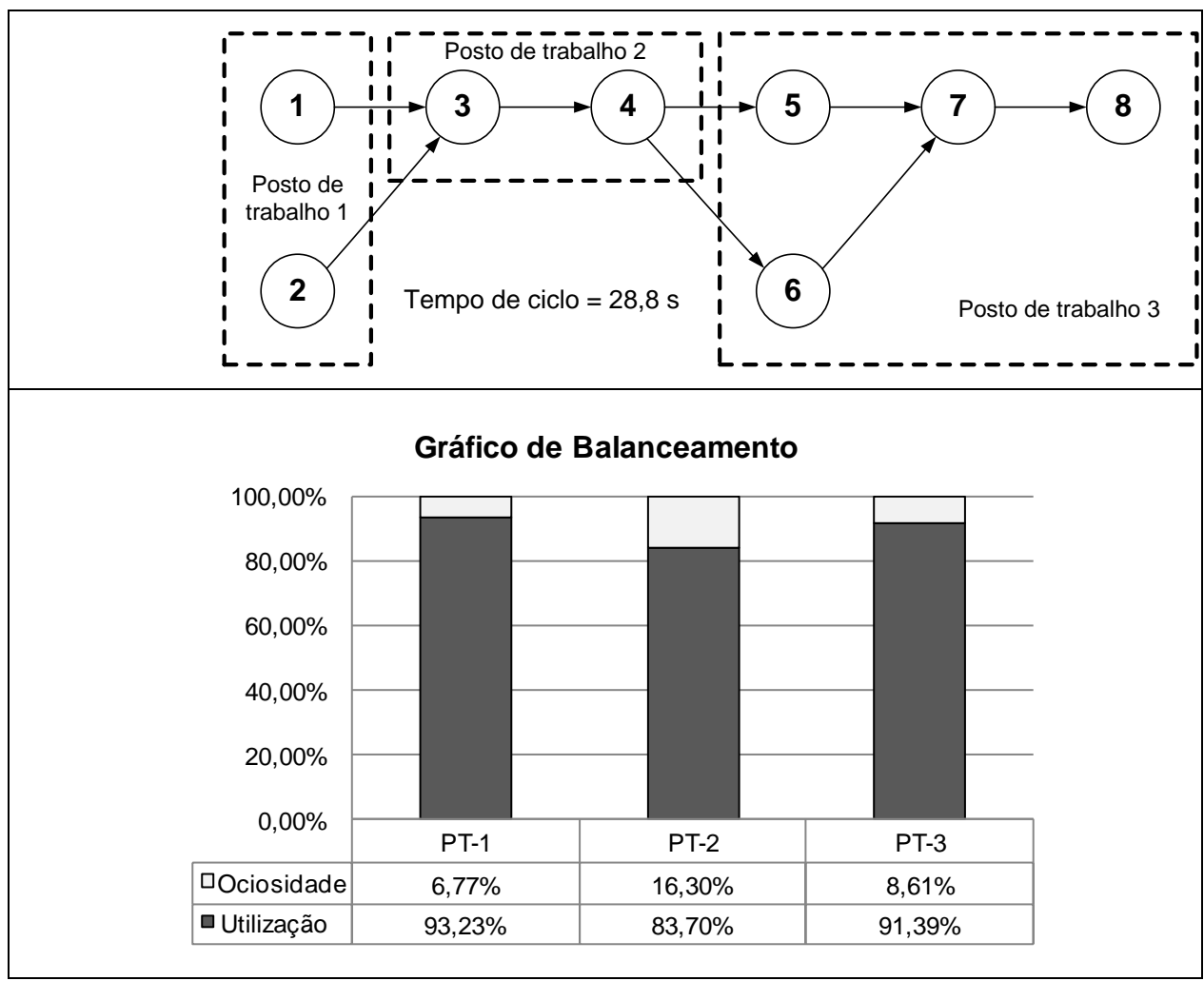

Depois do balanceamento de linha, os alunos prosseguiram no projeto do processo de montagem com a elaboração das rotinas de operações-padrão para cada posto de trabalho. Esse documento auxiliou os estudantes a praticar os conceitos de padronização de processos e serviu de base para a simulação da linha de montagem em operação. A rotina de operações-padrão do posto de trabalho PT-3 do exemplo anterior é apresentada na Figura 5.

Figura 5 - Rotina de operações-padrão do posto de trabalho PT-3.

\begin{tabular}{|c|c|c|c|c|c|c|c|c|c|c|c|c|c|c|c|}
\hline \multirow{2}{*}{\multicolumn{2}{|c|}{$\begin{array}{l}\text { Rotina de operações-padrão } \\
\text { Processo: Montagem do Robocano }\end{array}$}} & \multirow{2}{*}{\multicolumn{2}{|c|}{$\begin{array}{c}\text { Posto de trabalho: } \\
\text { PT-3 }\end{array}$}} & \multirow{2}{*}{\multicolumn{4}{|c|}{$\begin{array}{l}\text { Demanda: } 1000 \text { pçs./dia } \\
\text { Tempo de ciclo: } 28,8 \mathrm{~s}\end{array}$}} & \multirow{2}{*}{\multicolumn{2}{|c|}{$\begin{array}{l}\text { Data } \\
-11\end{array}$}} & \multirow{2}{*}{\multicolumn{4}{|c|}{$\begin{array}{l}\text { Operação manual: } \\
\text { Operação mecânica: } \\
\text { Deslocamento: }\end{array}$}} & \multirow{2}{*}{\multicolumn{2}{|c|}{ น"n }} \\
\hline & & & & & & & & & & & & & & & \\
\hline \multicolumn{2}{|r|}{ Operação } & \multicolumn{2}{|c|}{ Tempo (s) } & \multicolumn{12}{|c|}{ Tempo de operação (s) } \\
\hline № & Descrição & Manual & Máquina & 4 & 8 & 12 & & 16 & 20 & 24 & 28 & 32 & 3 & & 0 \\
\hline 1 & Montar braço 1 & 6,19 & - & & & & & & & & & & & & \\
\hline 2 & Montar braço 2 & 7,08 & - & & & & & & & & & & & & \\
\hline 3 & Montar tronco no quadril & 8,21 & - & & & & & & & & & & & & \\
\hline \multirow[t]{2}{*}{4} & Montar cabeça no tronco & 4,84 & - & & & & & & & & & & & & \\
\hline & Tempo total líquido: & 26,32 & - & & & & & & & & & & & & \\
\hline
\end{tabular}


Ao término da aplicação da dinâmica, os estudantes puderam compreender a relação da medição de tempos produtivos com o balanceamento de linhas. Essa relação dificilmente é abordada em aulas teóricas, nas quais a visão global do projeto de uma linha de montagem se perde em meio à fragmentação do ensino dos diferentes tópicos de Gestão da Produção.

\subsection{Aplicação 2: planejamento de necessidades de materiais (MRP)}

O objetivo da Aplicação 2 era simular a estruturação e o funcionamento de um sistema MRP, desde a elaboração da estrutura do produto até a programação de ordens de produção e de compra para cada componente. Neste caso, a situação simulada era a de uma fábrica que produzia uma grande variedade de modelos de ROBOCANO, com diferentes tempos e necessidades de processamento, fazendo com que a produção tivesse um fluxo intermitente e fosse organizada por lotes em um layout funcional (e não em uma linha de montagem como no exemplo anterior).

No início da atividade o professor descreveu a fábrica simulada, que contava com três centros de trabalho:

- CT1: responsável pela produção de quadris. Considerou-se que a produção de pernas e pés fossem submontagens desse mesmo centro de trabalho que antecediam a montagem final dos quadris. Essas submontagens seriam feitas em estações de trabalho específicas dentro do CT1 e necessitavam de ordens de produção separadas, derivadas das ordens de produção de quadris.

- CT2: responsável pela produção de troncos. Para os modelos que possuíam braços, considerou-se que a produção dos mesmos fossem submontagens que antecediam a montagem final dos troncos. Essas submontagens seriam feitas em estações de trabalho específicas dentro do CT2 e necessitavam de ordens de produção separadas, derivadas das ordens de produção de troncos.

- CT3: responsável pela produção de cabeças e pela montagem do produto final. Embora a produção de cabeças fosse feita no mesmo centro de trabalho da montagem final, elas possuíam estações de trabalho específicas e necessitavam de ordens de produção separadas, derivadas das ordens de produção dos produtos finais.

Na Aplicação 2 foram utilizados dois modelos de ROBOCANO (denominados de "Modelo A" e "Modelo B"), para que os alunos pudessem perceber as relações entre diferentes produtos em um mesmo sistema de programação da produção. Foram apresentadas as fotografias dos modelos e os centros de trabalho a eles relacionados, tal como mostra a Figura 6.

Os estudantes, já divididos em grupos, receberam o conjunto de peças de cada modelo e o roteiro da aplicação. Em linhas gerais, o roteiro continha os seguintes passos:

- Elaborar a estrutura do produto dos dois modelos de ROBOCANO. 
- Calcular as necessidades brutas de cada item das estruturas para uma demanda de "N" unidades.

- Considerando um dado programa-mestre de produção para um determinado horizonte de planejamento, programar a liberação de ordens de produção e de compra para cada item.

Figura 6 - Modelos utilizados e centros de trabalho relacionados.
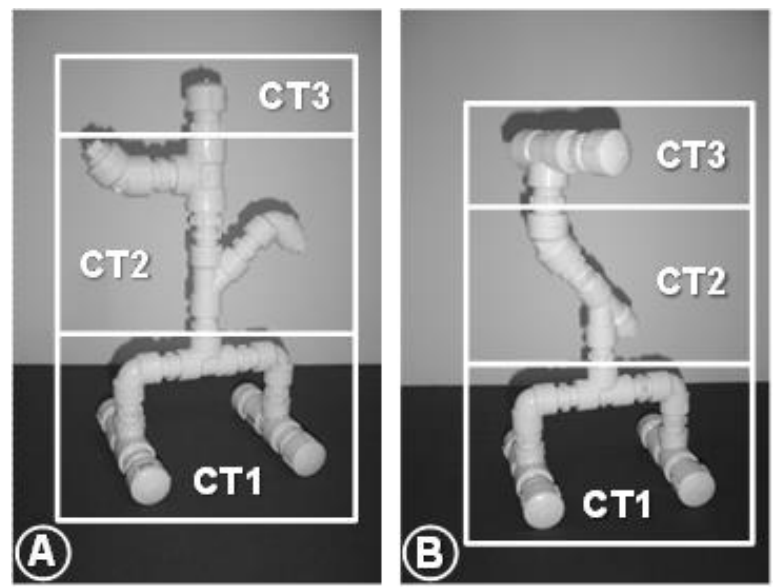

Diferentemente da Aplicação 1, na qual os alunos tinham a liberdade de definir o processo e agrupar as submontagens como quisessem, na Aplicação 2 foi necessário que o professor definisse exatamente o conjunto de peças que constituía cada parte do ROBOCANO. Para isso, eram apresentadas fotografias que mostram os componentes e suas submontagens, tal como exemplifica a Figura 7 para o Modelo A.

Figura 7 - Componentes e submontagens do Modelo A

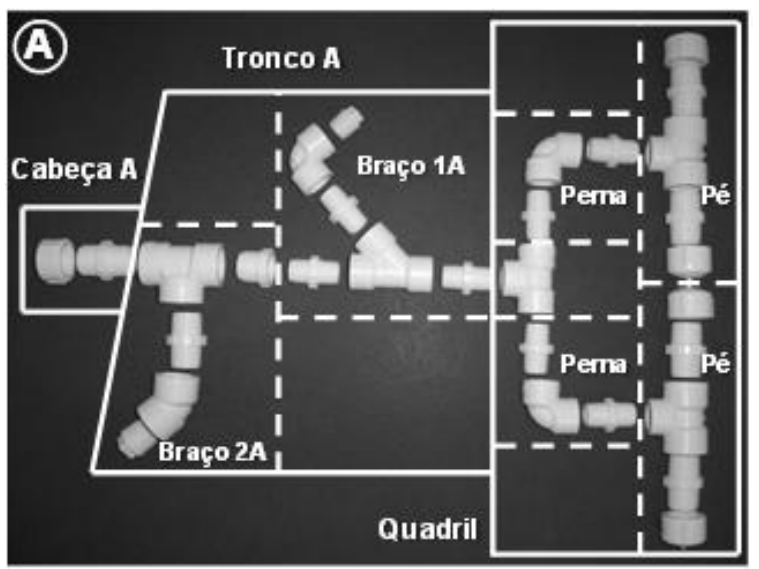

O estabelecimento dos centros de trabalho e das submontagens que necessitavam de ordens de produção indicou a forma que a estrutura do produto deveria ser construída. A Figura 8 apresenta a estrutura do produto para o Modelo A. 
A definição exata dos componentes de cada parte dos modelos foi necessária para que fossem obtidas as mesmas estruturas de produto entre os diferentes grupos de estudantes. Como neste caso seriam fornecidos dados de entrada para que os alunos pudessem "rodar" o MRP, o professor deveria conhecer previamente as estruturas que seriam formadas, já que os dados de entrada seriam preparados com antecedência. Alternativamente, pode-se conceder um maior grau de liberdade para os alunos quando o objetivo da atividade for somente desenhar a estrutura do produto.

Figura 8 - Estrutura do produto para o Modelo A

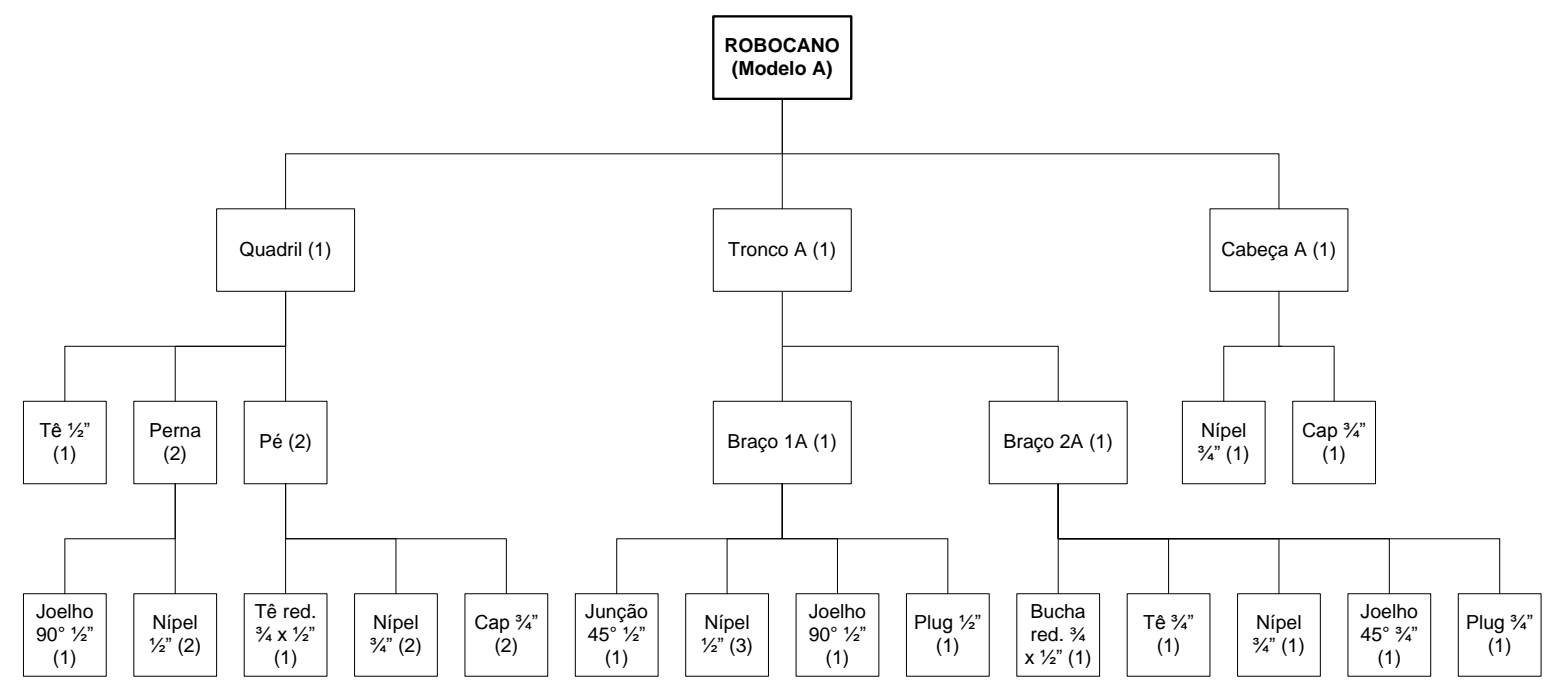

A partir das estruturas dos produtos, era possível calcular as necessidades brutas de cada item sempre que o professor fornecia valores de demanda para os modelos A e B. No entanto, esse era apenas um exercício parcial, já que o objetivo era programar as ordens de produção e de compra para cada item, a partir de um determinado programa-mestre de produção. Para um determinado horizonte de planejamento, eram fornecidos os seguintes dados de entrada para cada elemento da estrutura:

- Políticas e tamanhos de lote (lote fixo, lote-a-lote - L4L, período fixo, etc.);

- Estoque de segurança;

- Estoque disponível;

- Lead time;

- Recebimentos programados;

- Demanda prevista e demanda confirmada para cada modelo de ROBOCANO.

Com os dados fornecidos, os estudantes deveriam preencher as planilhas do MRP para cada item e observar as relações entre os diferentes elementos das estruturas dos produtos. Para 
exemplificar, a Figura 9 apresenta algumas das planilhas preenchidas pelos estudantes e destaca a relação entre elementos das estruturas. Nesse caso, o item "quadril”, que é comum para os dois modelos, recebe necessidades brutas provenientes da liberação de ordens de produção do Modelo A e do Modelo B.

Nas aulas teóricas sobre o sistema MRP os alunos geralmente se satisfazem em aprender como fazer os cálculos nas planilhas, mesmo que não compreendam completamente sua dinâmica de funcionamento. A Aplicação 2 permitiu com que os estudantes pudessem interagir com o funcionamento de um sistema MRP por meio de um exemplo tangível, adquirindo uma visão global e mais crítica sobre o assunto.

Figura 9 - Exemplos de planilhas preenchidas e suas relações

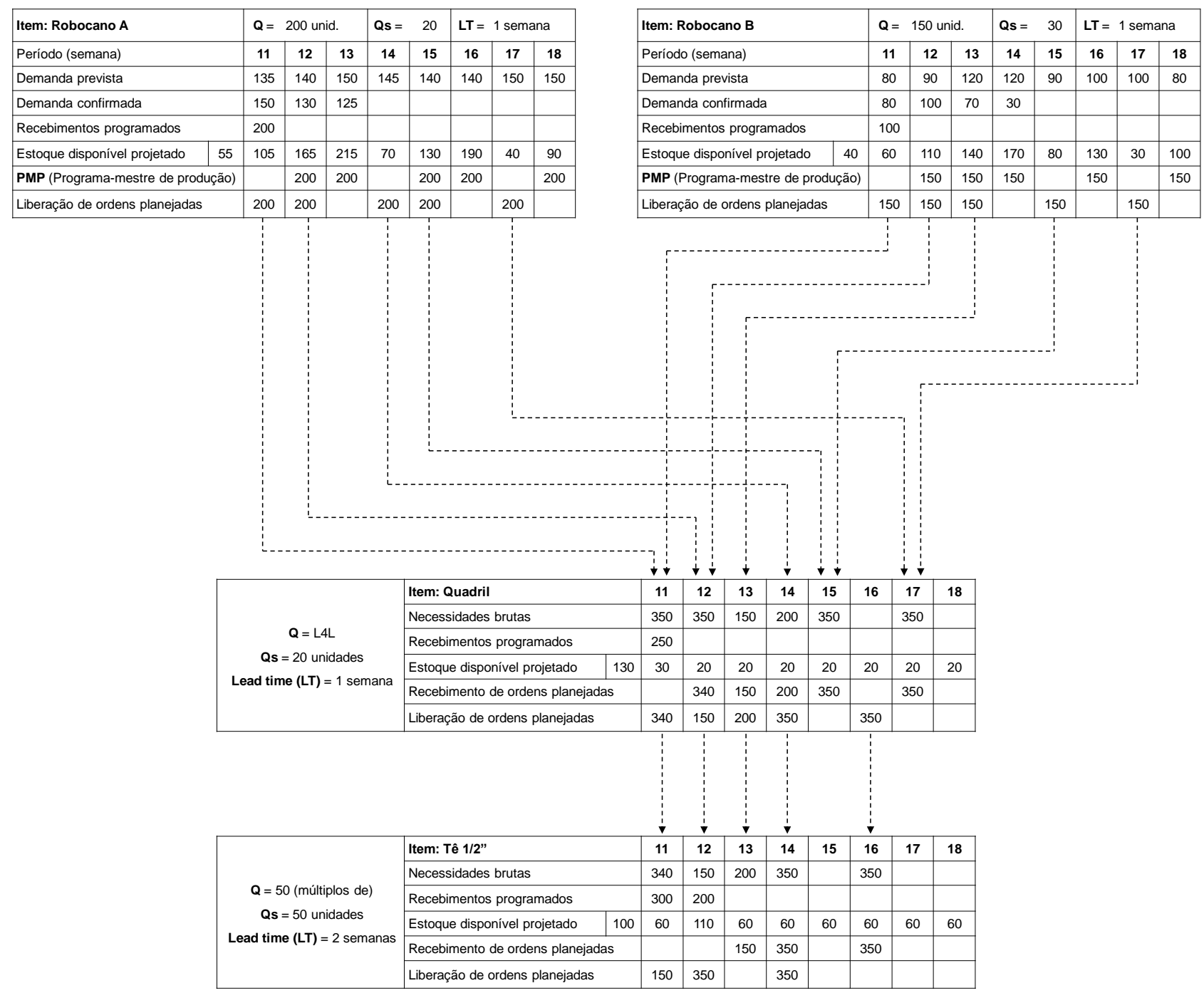

\subsection{Aplicação 3: programação puxada com o sistema kanban}

Esta aplicação simula a mesma estrutura de produção da Aplicação 2, com três centros de trabalho distribuídos em um layout funcional. A diferença é que na Aplicação 3 o sistema de 
programação empurrada (lógica do MRP) deveria ser substituído pelo sistema de programação puxada, operacionalizado pela utilização de cartões kanban. Nesse sentido, o objetivo dessa aplicação era simular a operação de um sistema kanban, no qual as ordens de produção não seriam mais emitidas por um sistema centralizado de PCP, mas sim, pelos clientes internos que "puxam" a produção de seus fornecedores internos por meio dos cartões kanban.

Aproveitando a familiarização prévia dos alunos com a atividade e permitindo a comparação entre a programação empurrada com a programação puxada, foram utilizados os mesmos modelos da Aplicação 2 (Modelo A e Modelo B). Os grupos de estudantes foram formados em torno dos centros de trabalho, pois nesse caso eles seriam os próprios executores do processo de produção. Após a alocação dos "trabalhadores" nos centros de trabalho, o professor distribuiu o seguinte roteiro, juntamente com os dados necessários para o dimensionamento do sistema kanban:

- Desenhar os cartões kanban contendo as informações que forem necessárias.

- Dimensionar os supermercados, de acordo com os dados fornecidos para o cálculo do número de kanbans.

- Projetar o painel ou quadro porta-kanban, estabelecendo as zonas de prioridade (sinalizando pelas cores verde, amarelo e vermelho).

- Simular a operação do sistema a partir da programação nivelada enviada ao centro de trabalho responsável pela montagem de produtos finais.

Para simplificar a operação, foi dispensada a necessidade de emissão de kanbans para as submontagens dos centros de trabalho (cabeças, braços, pernas e pés). Dessa forma, foram utilizados kanbans somente para requisitar quadris ou troncos completos dos dois modelos. Devido às limitações de espaço no laboratório didático onde ocorreu a aplicação, foi simulado o sistema kanban de cartão único, com apenas um supermercado após cada centro de trabalho. A Figura10 apresenta o fluxo de produção simulado na Aplicação 3. 
Figura 10 - Representação esquemática do fluxo de produção na Aplicação 3.

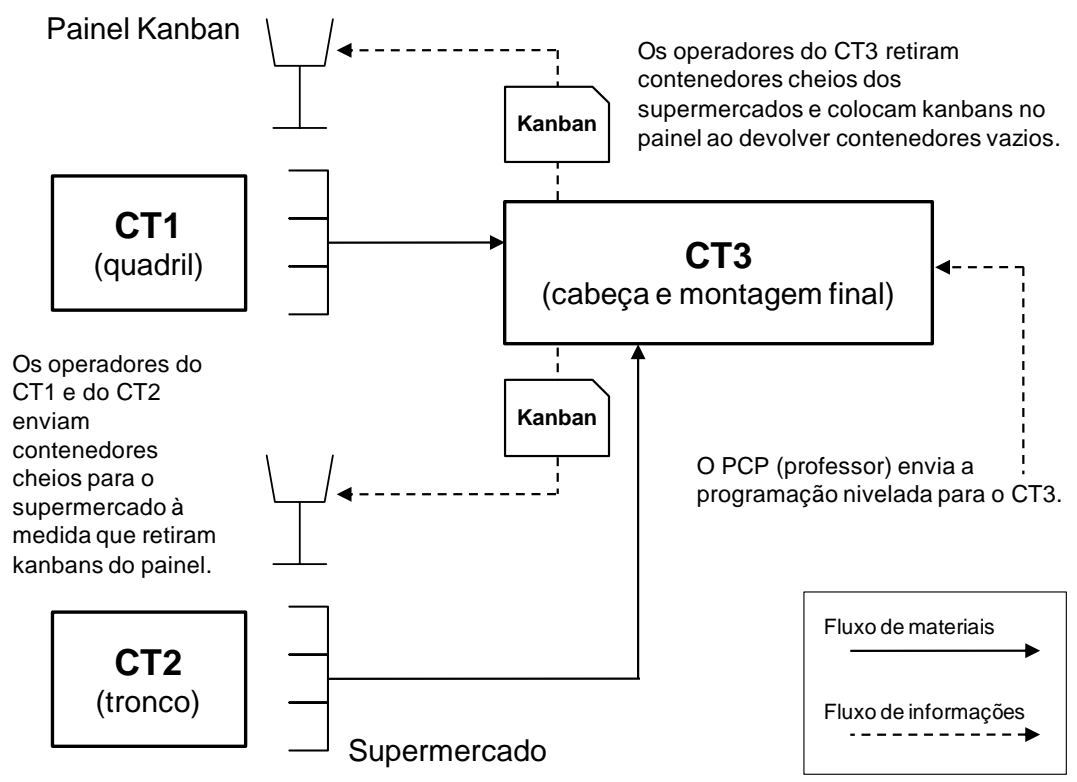

O processo se iniciava com o envio de ordens de produção de produtos finais para CT3. Neste caso, o professor fazia o papel do órgão de PCP da fábrica simulada e procurava nivelar o programa-mestre de produção dentro da lógica heijunka, preconizada pelo sistema just-in-time de programação. Então, o professor enviava um programa de produção mista, mesclando os modelos A e B (como por exemplo, AABAABAABAAB), de acordo com a quantidade e o mix de produtos que se pretendia montar. O processo era repetido com diferentes programas nivelados de produção.

Ao receber o programa de montagem de produtos finais, os operadores do CT3 retiravam quadris e troncos dos supermercados e depositavam kanbans nos painéis ao devolver os contenedores vazios. A produção era acionada no CT1 e no CT2 pelos kanbans colocados nos painéis, que funcionavam como ordens de produção para o sistema puxado.

O formato dos cartões kanban era definido pelos próprios alunos, que os desenhavam em pedaços de papel e os colocavam dentro de envelopes de plástico do tipo porta-crachá. Os contenedores foram simulados com caixas de papelão e os painéis porta-kanban foram feitos pelos alunos com folhas de papel. Os painéis foram afixados na parede, de forma que os kanbans pudessem ser pendurados neles.

Ao simular a operação do sistema kanban, os estudantes praticaram a lógica da programação puxada, por meio da coordenação do fluxo de informações com o fluxo de materiais. Embora o sistema kanban adote a simplicidade como princípio fundamental, os alunos geralmente têm dificuldade em compreender seu funcionamento em aulas teóricas. A mudança do papel de espectador para o papel de participante do processo de produção fez com que os estudantes aprendessem a dinâmica do sistema kanban por meio de sua experiência prática. 


\section{Análise preliminar dos resultados}

Conforme foi mencionado na seção 4, que explica a metodologia de desenvolvimento do Projeto ROBOCANO, foi aplicado um questionário para verificar os efeitos da dinâmica nos estudantes. Depois da aplicação, as respostas foram tabuladas e organizadas nos gráficos apresentados na Figura 11.

Como é possível observar na Figura 11, a maioria dos estudantes avaliou positivamente as aplicações da dinâmica. Nas quatro questões, as respostas do tipo "concordo" e "concordo totalmente" foram predominantes. No questionário também havia um espaço para comentários e sugestões. Nesse espaço, a maioria dos alunos elogiou a iniciativa e pediu que atividades desse tipo fossem feitas com uma maior frequência.

Os percentuais de $42 \%$ de respostas do tipo "concordo totalmente" e $45 \%$ do tipo "concordo" associados à questão do trabalho em equipe, reforçam o alinhamento da dinâmica proposta com os modelos de educação cooperativa e educação colaborativa, nos quais a interação entre os membros dos grupos sociais representa um fator determinante para o aprendizado.

A dinâmica também corrobora para a filosofia da Aprendizagem Baseada em Problemas (PBL), uma vez que os alunos participam da atividade quando ainda não têm um conhecimento consolidado sobre os assuntos envolvidos. Nesse sentido, a atividade proposta representa um problema que motiva os estudantes a buscar as ferramentas necessárias para resolvê-lo.

Figura 11 - Respostas dos estudantes na aplicação dos questionários.

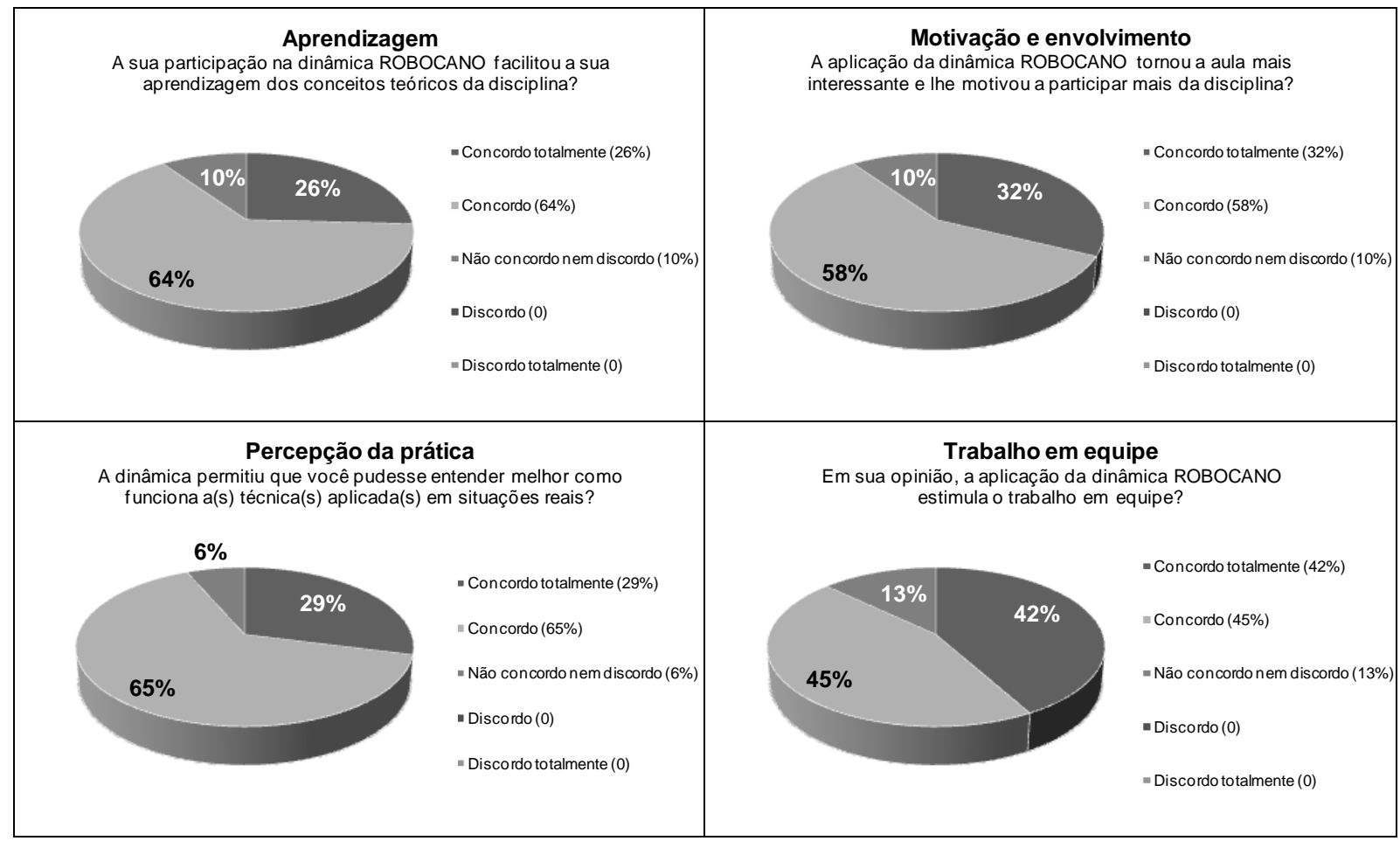


Um diferencial da dinâmica apresentada em relação aos jogos didáticos com regras prédefinidas é que os alunos não se sentem em um jogo, mas em uma situação real. Por meio da dinâmica, eles geram e analisam dados de um processo real, criado a partir de um contexto simulado. Além de contribuir para a motivação e o envolvimento dos estudantes, essa característica contribui para que o aluno tenha uma percepção mais clara de como as técnicas estudadas atuam na prática das empresas.

Em relação à abordagem LEGO $^{\circledR}$, o ROBOCANO possui a vantagem de ter um custo mais baixo, uma característica que viabiliza a sua aplicação em diferentes situações que apresentam limitações de recursos financeiros. Além disso, o ROBOCANO é constituído por um material mais resistente e mais durável que o $\mathrm{LEGO}^{\circledR}$, admitindo inclusive o reaproveitamento de peças que já foram utilizadas na construção civil. Outro aspecto que merece destaque é que a inexistência de brinquedos feitos com conexões hidráulicas favorece ainda mais a criatividade dos estudantes, que não as associam a qualquer outro artefato de origem infantil.

Entretanto, cabe ressaltar que a criatividade na utilização do ROBOCANO está limitada pela variedade e pela quantidade de peças que se dispõe. À medida que se ampliam as possibilidades de aplicação, mais peças são requeridas. Portanto, o planejamento e a preparação da aplicação são indispensáveis para a adoção do ROBOCANO como recurso didático.

\section{Considerações finais}

As transformações na sociedade atual e a intensificação dos fluxos informacionais têm mudado o perfil dos estudantes universitários e, consequentemente, a maneira que eles aprendem. Esse novo contexto demanda uma abordagem diferente da prática docente tradicional e justifica o crescente interesse em melhorar a relação ensino-aprendizagem por meio de dinâmicas inovadoras.

O projeto ROBOCANO, apresentado neste artigo, representou uma alternativa para envolver os estudantes de Engenharia de Produção em atividades que enfatizavam a experiência e a participação ativa para a construção do conhecimento. Com simples conexões de PVC, foi possível constatar na prática o aumento da motivação dos estudantes e a possibilidade integrar conceitos e técnicas de Gestão da Produção em um único exercício didático, situação que dificilmente seria conseguida na abordagem tradicional de sala de aula.

A dinâmica ROBOCANO também contribui para incrementar as aulas em laboratórios didáticos de Engenharia de Produção. Seguindo uma tendência já sinalizada pela Associação Brasileira de Engenharia de Produção, a dinâmica proposta oferece possibilidades de realização de atividades práticas que justificam a utilização cada vez maior de laboratórios dedicados ao ensino de conteúdos específicos do curso. 
De fato, a atividade realizada com conexões hidráulicas representa um exercício vivencial que contribui para a redução da lacuna entre teoria e prática no ensino de Gestão da Produção. Em geral, os engenheiros de produção somente visualizam atividades práticas quando, recém-formados, se deparam com o processo produtivo ocorrendo in loco. Na dinâmica ROBOCANO, os estudantes são induzidos a simular um processo real a partir de um produto fictício.

No entanto, vale ressaltar que o atendimento aos objetivos de aprendizagem depende do planejamento prévio por parte do professor. Nesse sentido, o papel facilitador do professor na preparação e na condução do processo é fundamental para que se possa tirar proveito de todos os benefícios do método. Nos três tipos de aplicação que foram relatados neste texto, o professor estimulava a autonomia dos estudantes para resolver os problemas que lhes eram colocados e, ao mesmo tempo, induzia os grupos de trabalho a explorar métodos de solução que favorecessem a sua aprendizagem.

A grande variedade de situações que se aplica o princípio de intercambialidade de peças indica um caminho para a continuidade deste trabalho. Por isso, é importante que a dinâmica ROBOCANO seja adaptada para o ensino de outros tópicos de Engenharia de Produção, como por exemplo, projeto de fábrica, ergonomia do posto de trabalho, engenharia do produto, planejamento e controle de qualidade, dentre outros.

De um modo geral, a dinâmica apresentada neste artigo chama a atenção para a necessidade de criar atividades que estimulem o estudante a participar mais intensamente das aulas, aplicando técnicas que passam a fazer mais sentido para ele após a sua aprendizagem experiencial.

\begin{abstract}
The paper aims to present a hands-on activity for Production Management education that proposes the use of PVC fittings, commonly utilized in water pipes, to simulate assembly operations which are usual in industry. The teaching method followed the logic of the models of cooperative and collaborative learning and was developed in an action research approach, inasmuch as the proposed activity was tested and improved during the applications made in teaching laboratories. The applicability of the method was confirmed with the positive feedback from the students involved in the exercises, obtained through a survey conducted after a set of applications. The activity with pipe fittings represents a practical exercise that contributes to the reduction of the gap between theory and practice in Production Management teaching. Using simple and low cost materials, the students are induced to simulate a real process from a fictitious product.
\end{abstract}

Key-words: teaching activities, experiential learning, production management.

\title{
Referências
}

ABEPRO. Associação Brasileira de Engenharia de Produção. Disponível em: 〈http://www.abepro.org.br>. Acesso em: 25 mai. 2012. 
AMMAR, S.; WRIGHT, R. Experiential learning activities in operations management. International Transactions in Operational Research, v. 6, n. 2, p. 183-197, 1999.

cross ref

BARDON, T.; JOSSERAND, E. Why do we play the games? Exploring institutional and political motivations.

Education + Training, v. 51, n. 5/6, p. 460-475, 2009.

BENJAMIN, C.; KEENAN, C. Implications of introducing problem-based learning in a traditionally taught course.

Engineering Education: Journal of the Higher Education Academy Engineering Subject Centre, v. 1, n. 1, p. 1-5, 2006.

BÜRGI, P.; ROOS, J. Images of strategy. European Management Journal, v. 2, n. 1, p. 69-78, 2003.

cross'

CÓ, F. A.; CÓ, M. A.; MERIGUETI, B. A. O "heyjunka didático": um jogo interdisciplinar que auxilia na elevação da aprendizagem sobre a produção enxuta. In: ENCONTRO NACIONAL DE ENGENHARIA DE PRODUÇÃO, 28, 2008, Rio de Janeiro - RJ. Anais... Rio de Janeiro: ABEPRO, 2008. CD-ROM.

CORRÊA, H. L.; GIANESI, I. G. N.; CAON, M. Planejamento, programação e controle da produção: MRP II/ERP: conceitos, uso e implantação. 5.ed. São Paulo: Atlas, 2007.

COSTA, A. C. F.; JUNGLES, A. E. O mapeamento do fluxo de valor aplicado a uma fábrica de montagem de canetas simulada. In: ENCONTRO NACIONAL DE ENGENHARIA DE PRODUÇÃO, 26, 2006, Fortaleza - CE. Anais... Fortaleza: ABEPRO, 2006. CD-ROM.

COUGHLAN, P.; COGHLAN, D. Action research for operations management. International Journal of Operations \& Production Management, v. 22, n. 2, p. 220-240, 2002.

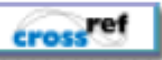

DEPEXE, M. D. et al. Apresentação de um jogo didático como ferramenta de apoio ao ensino da produção enxuta. Revista Gestão Industrial, v. 02, n. 04, p. 140-151, 2006.

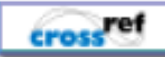

DILLENBOURG, P. What do you mean by collaborative learning? In: DILLENBOURG, P. (Comp.). Collaborativelearning: cognitive and computational approaches. Oxford: Elsevier, 1999. p. 1-19.

EDEN, C.; HUXHAM, C. Action research for management research. British Journal of Management, v. 7, n. 1, p. 75-86, 1996.

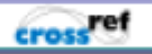

FORD, R. C. The Springfield Armory's role in developing interchangeable parts. Management Decision, v. 43, n. 2, p. 265-277, 2005.

GAITHER, N.; FRAZIER, G. Administração da produção e operações. 8.ed. São Paulo: Pioneira Thomson Learning, 2001.

GOKHALE, A. A. Collaborative learning enhances critical thinking. Journal of Technology Education, v. 7, n. 1, p. 22-30, 1995.

HAAPASALO, H.; HYVÖNEN, J. Simulating business and operations management - a learning environment for the electronics industry. International Journal of Production Economics, v. 73, n. 3, p. 261-272, 2001.

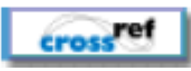

JOHNSON, D. W.; JOHNSON, R. T.; STANNE, M. B. Cooperative learning methods: a meta-analysis. p. 1-17, 2000. Disponível em: <www.tablelearning.com/uploads/file/exhibit-b.pdf>. Acesso em: 15 jun. 2010.

KRAJEWSKY, L.; RITZMAN, L.; MALHOTRA, M. Administração de produção e operações. 8.ed. São Paulo: Prentice Hall, 2009. 
LAGE JUNIOR, M.; FERNANDES, F. C. F. Projeto de um simulador analógico do sistema kanban para fins educacionais. In: SIMPÓSIO DE ENGENHARIA DE PRODUÇÃO, 12, 2005, Bauru - SP. Anais... Bauru: UNESP, 2005. CD-ROM.

LEWIS, M. A.; MAYLOR, H. R. Game playing and operations management education. International Journal of Production Economics, v. 105, n. 1, p. 134-149, 2007.

cross ref

LUSTOSA, L. J. et al. Planejamento e controle da produção. Rio de Janeiro: Elsevier, 2008.

MAGILL, J.; ROY, S. Chips for everyone: developing creativity in engineering and initial teacher education.

Engineering Education: Journal of the Higher Education Academy Engineering Subject Centre, v. 2, n. 1, p. 4046, 2007.

MELLO, J. Developing managerial skills: a framework to define the faculty role in linking field-based learning to classroom learning. Journal of Workplace Learning, v. 10, n. 6/7, p. 292-295, 1998.

cross ref

MOSCINSKI, J. Changing tools and methods in engineering education. In: INTERNATIONAL CONFERENCE ON ENGINEERING EDUCATION, 2007, Coimbra - Portugal. Proceedings... Coimbra: ICEE, 2007. p. 1-5.

PANITZ, T. A definition of collaborative vs. cooperative learning. p. 1-3, 1996. Disponível em: <http://www.friendsofchalkbytes.org/uploads/cb1398ec-0683-4f10-8909-

6af19fb84986/A\%20Definition\%20of\%20Collaborative\%20vs\%20Cooperative\%20Learning.doc>. Acesso em: 15 jun. 2010.

PAXTON, J. A short, simple learning curve classroom exercise. Decision Sciences Journal of Innovative Education, v. 1, n. 2, p. 303-307, 2003.

cross ref

ROSSITER, J. A. New games for use in lectures to improve student learning. In: INTERNATIONAL CONFERENCE ON ENGINEERING EDUCATION, 2007, Coimbra - Portugal. Proceedings... Coimbra: ICEE, 2007. p. 1-6.

SCHMENNER, R. W. Looking ahead by looking back: swift, even flow in the history of manufacturing. Production and Operations Management, v. 10, n. 1, p. 87-96, 2001.

cross ref

SLAVIN, R. Research on cooperative learning and achievement: what we know, what we need to know. p. 1-18, 1995. Disponível em: <http://socialfamily535.pbworks.com/f/slavin1996\%5d.pdf>. Acesso em: 15 jun. 2010.

SMEDS, R. Guest editorial: Simulation for accelerated learning and development in industrial management. Production Planning \& Control, v. 14, n. 2, p. 107-110, 2003.

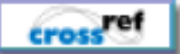

SMITH-DANIELS, D. E.; SMITH-DANIELS, V. L. Trade-offs, biases, and uncertainty in project planning and execution: a problem-based simulation exercise. Decision Sciences Journal of Innovative Education, v. 6, n. 2, p. 313-341, 2008.

cross ref

SNIDER, B. R.; ELIASSON, J. B. Push versus pull and mass customization: a Lego Inukshuk demonstration. Decision Sciences Journal of Innovative Education, v. 7, n. 2, p. 411-416, 2009.

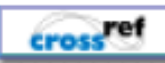

TUBINO, D. F. Planejamento e controle da produção: teoria e prática. 2.ed. São Paulo: Atlas, 2009.

YEO, R. Problem-based learning: lessons for administrators, educators and learners. International Journal of Educational Management, v. 19, n. 7, p. 541-551, 2005. 


\section{Dados dos autores:}

Nome completo: Luciano Costa Santos

Filiação institucional: Universidade Federal da Paraíba

Departamento: Engenharia de Produção

Função ou cargo ocupado: Professor

Endereço completo para correspondência: UFPB - Universidade Federal da Paraíba, Departamento de Engenharia de Produção, Centro de Tecnologia - Campus I, Bloco G, Cidade Universitária, João Pessoa - PB, Brasil, Cx. Postal: 5045, CEP: 58.051-970

Telefones para contato: (83) 3216-7685, (83) 9632-6616

e-mail: luciano@ct.ufpb.br

\section{Nome completo: Cláudia Fabiana Gohr}

Filiação institucional: Universidade Federal da Paraíba

Departamento: Engenharia de Produção

Função ou cargo ocupado: Professora

Endereço completo para correspondência: UFPB - Universidade Federal da Paraíba, Departamento de Engenharia de Produção, Centro de Tecnologia - Campus I, Bloco G, Cidade Universitária, João Pessoa - PB, Brasil, Cx. Postal: 5045, CEP: 58.051-970

Telefones para contato: (83) 3216-7817, (83) 9608-4224

e-mail: claudiagohr@ct.ufpb.br

\section{Nome completo: Milton Vieira Junior}

Filiação institucional: Universidade Nove de Julho

Departamento: Engenharia de Produção

Função ou cargo ocupado: Professor

Endereço completo para correspondência: Av. Francisco Matarazzo, 612, Água Branca, São Paulo SP, Brasil, CEP: 05.001-100.

Telefone para contato: (11) 3665-9304

e-mail:mvieirajr@uninove.br 